\title{
ANALYSIS OF THE CLINICAL PROFILE AND OUTCOMES OF PATIENTS PRESENTING WITH STRESS CARDIOMYOPATHY AFTER SUICIDAL HANGING TO A MULTIDISCIPLINARY ICU IN SOUTH INDIA
}

\author{
Renuka M. K1 , BabySailaja K²
}

1Professor, Department of Anaesthesiology, Sri Ramachandra Medical College and Research Institute, Chennai, Tamilnadu, India.

${ }^{2}$ Assistant Professor, Department of Critical Care Medicine, Sri Ramachandra Medical College and Research Institute, Chennai, Tamilnadu, India.

\section{ABSTRACT}

\section{BACKGROUND}

Stress cardiomyopathy, a reversible left ventricular dysfunction, following suicidal hanging is an uncommon clinical entity among intensive care unit (ICU) admissions. As there is a dearth of data on this condition, we intended to study the clinical profile and outcomes of patients admitted to our multidisciplinary ICU with stress cardiomyopathy following an attempted suicidal hanging.

\section{MATERIALS AND METHODS}

An observational study was conducted for a period of seven years on consecutive suicidal hanging patients admitted to the ICU with stress cardiomyopathy Demographic details, severity of illness, interventions and outcomes of these patients were studied.

\section{RESULTS}

During the study period, 19 patients were admitted to our multidisciplinary ICU with left ventricular dysfunction compatible with stress cardiomyopathy following an attempted suicide by hanging. The patients in the study were young with a mean age of 26.89 years and showed a female predominance of $63 \%$. Non survivors had a significantly low Glasgow Coma Scale (GCS) (Mean=3.67), high mean Acute Physiology and Chronic Health Evaluation II (APACHE II) score (31.33) and low mean ejection fraction (25.83\%) compared to survivors. Mechanical ventilation and vasopressor support were required in $89.5 \%$ and $68.4 \%$ patients respectively. We observed a mortality rate of $31.6 \%(n=6)$. Hospital stay and ICU free days were significantly shorter in non survivors reflecting their critical presentation from the time of admission. Due to the short course of stay in hospital of both survivors and non survivors we could not assess the reversal of the cardiac dysfunction in our study.

\section{CONCLUSION}

Stress cardiomyopathy being a reversible condition and considering the high mortality observed in our study further studies with a large sample size is needed for a better understanding of this condition in suicidal hanging patients.

\section{KEY WORDS}

Suicidal Hanging, Stress Cardiomyopathy, Pulmonary Oedema, Ejection Fraction, Reversed Takotsubo

HOW TO CITE THIS ARTICLE: Renuka MK, BabySailaja K. Analysis of the clinical profile and outcomes of patients presenting with stress cardiomyopathy after suicidal hanging to a multidisciplinary ICU in South India. J. Evolution Med. Dent. Sci. 2019;8(12): 826829, DOI: $10.14260 /$ jemds/2019/184

\section{BACKGROUND}

Hanging is one of the common methods of attempted suicide in India.(1) In suicidal hanging factors like placement of knot, type of ligature material, height of suspension will influence the mechanism of death.(2) Hanging can be partial hanging (The body remains in contact with the ground) or complete hanging (The body will not come in contact with the ground). In most situations the victims die at the scene and hence there is paucity of data on the mechanisms of death in suicidal hanging. Victims who are identified early reach the emergency room either restless or unconscious. Patients frequently present with haemodynamic instability or pulmonary oedema.

'Financial or Other Competing Interest': None.

Submission 18-02-2019, Peer Review 10-03-2019,

Acceptance 12-03-2019, Published 25-03-2019.

Corresponding Author:

Dr. BabySailaja K,

Assistant Professor

Department of Critical Care Medicine,

Sri Ramachandra Medical College and

Research Institute, Chennai,

Tamilnadu, India.

E-mail: sailajaroop@gmail.com

DOI: $10.14260 /$ jemds/2019/184

\section{(c) $(1)(9)$}

The underlying cause may be due to a neurologic injury or stress cardiomyopathy. The occurrence of stress cardiomyopathy following a physical or emotional insult is well established.(3,4)

At present, data on stress cardiomyopathy in suicidal hanging is limited to case reports and case series. For this reason, we intended to analyse the clinical profile and outcomes of this population presenting to our multidisciplinary intensive care unit (ICU).

\section{Aims and Objectives \\ The aim of the study was to evaluate the clinical profile of suicidal hanging patients admitted to a multidisciplinary intensive care unit with stress cardiomyopathy. The outcomes analysed were in-hospital mortality rate, hospital length of stay (LOS), ICU LOS, ICU free days and ventilator free days.}

\section{MATERIALS AND METHODS}

An observational study was conducted for a period of 7 years on all patients who got admitted to the multidisciplinary ICU with haemodynamic instability or pulmonary oedema following attempted suicidal hanging. Those patients who had left ventricular dysfunction suggestive of stress cardiomyopathy were enrolled into the study. 
Data collected included age, sex, mode of hanging, Glasgow Coma Scale (GCS) at admission, whether patient was referred from outside and lead time (time taken to reach the emergency department from the time of identifying the victim at the scene). The admission Acute Physiology and Chronic Health Evaluation II (APACHE II), (5) Sequential Organ Failure Assessment (SOFA)(6) score on admission and after 48 hours were recorded to assess the severity of illness of the patients. All patients were evaluated with chest $\mathrm{X}$ ray, computerised tomography (CT) of cervical spine, CT brain, echocardiography and arterial blood gas (ABG). The presence of/development of pulmonary oedema calls for invasive mechanical ventilation and requirement for vasopressor support were recorded.

The primary outcome studied was in-hospital mortality rate. Hospital LOS, ICU LOS, ICU free days, ventilator days and ventilator free days were the secondary outcomes measured.

Statistical analysis of the data was performed using Statistical Package for Social Science (SPSS, version 17) for
Microsoft windows. Descriptive statistics were presented as numbers and percentages. The continuous variables were expressed as mean with standard deviation and median with interquartile range. Independent sample student t test / Mann Whitney test and Chi square test were used as applicable. A p value $<0.05$ was considered statistically significant.

\section{RESULTS}

During the study period, 19 patients were admitted to the multidisciplinary ICU with stress cardiomyopathy following an attempted suicidal hanging and carried a mortality rate of $31.6 \%(n=6)$. Except for one elderly female all the patients in the study were young with a mean age (yrs.) of $26.89 \pm 9.7$. The survivors were significantly younger than non survivors [23.46 \pm 3.87 vs $34.33 \pm 14.5$, $(p=0.019)]$. Sixty three percent $(n=12)$ of patients were female and the mode of hanging was partial hanging in about $74 \%(\mathrm{n}=14)$ patients. (Table 1$)$

\begin{tabular}{|c|c|c|c|c|}
\hline Characteristic & Total & Survivors & Non-Survivors & p-Value \\
\hline $\mathrm{n}, \%$ & 19 & $13(68.4)$ & $6(31.6)$ & \\
\hline Age, Mean \pm SD & $26.89 \pm 9.70$ & $23.46 \pm 3.87$ & $34.33 \pm 14.5$ & 0.019 \\
\hline Sex, n (\%) & & & & 0.82 \\
\hline Male & $7(36.8)$ & $5(71.4)$ & $2(28.6)$ & \\
\hline Female & $12(63.2)$ & $8(66.7)$ & $4(33.3)$ & \\
\hline Mode of Hanging, $n(\%)$ & & & & 0.11 \\
\hline Partial & $14(73.7)$ & $11(78.6)$ & $3(21.4)$ & \\
\hline Complete & $5(26.3)$ & $2(40)$ & $3(60)$ & \\
\hline Mode of Admission, $\mathrm{n}(\%)$ & & & & 0.91 \\
\hline Direct & $13(68.4)$ & $9(69.2)$ & $4(30.8)$ & \\
\hline Referred & $6(21.6)$ & $4(66.7)$ & $2(33.2)$ & \\
\hline Pulmonary Oedema, n (\%) & $14(73.7)$ & $9(64.3)$ & $5(35.7)$ & 0.51 \\
\hline Abnormal CT Brain, n (\%) & $7(36.8)$ & $4(57)$ & $3(43)$ & 0.41 \\
\hline Mechanical Ventilation, n (\%) & $17(89.5)$ & $11(64.7)$ & $6(35.3)$ & 0.31 \\
\hline Vasopressor Support at $24 \mathrm{~h}, \mathrm{n}(\%)$ & $13(68.4)$ & $7(53.8)$ & $6(46.2)$ & 0.68 \\
\hline Vasopressor Support at $48 \mathrm{~h}, \mathrm{n}(\%)$ & $13(68.4)$ & $8(61.5)$ & $5(38.5)$ & 0.68 \\
\hline Lead Time, (days) Mean \pm SD & $1.01 \pm 0.62$ & $0.93 \pm 0.67$ & $1.18 \pm 0.50$ & 0.26 \\
\hline \multicolumn{5}{|c|}{ Table 1. Clinical Characteristics of Patients with Stress Cardiomyopathy Following Suicidal Hanging } \\
\hline $\mathrm{n}=$ Number of patien & ercentage: SD & d Deviation; C & erized tomogra & \\
\hline
\end{tabular}

The lead time to ER was 1.01 days and about $32 \%(n=6)$ patients received treatment at other facilities before reaching the ER. Pulmonary oedema developed in about $74 \%(n=14)$ of patients and $10 \%(n=2)$ had aspiration pneumonitis.

The GCS was less than seven in $79 \%(n=15)$ of patients (mean GCS of $5.89 \pm 3.3$ ). Non survivors had a significantly low GCS at admission when compared to survivors, $[3.67 \pm 1.39$ vs $6.92 \pm 3.45$, $(p=0.017)]$.The admission APACHE II score was significantly higher in non survivors than survivors [31.33 \pm 2.73 vs $21.62 \pm 6.0,(\mathrm{p}=0.002)]$. The maximum APACHE II score observed in our study population was 34 . Though the admission SOFA score were comparable in both groups, the SOFA score at $48 \mathrm{hr}$ was low in survivors as they recovered rapidly with supportive treatment. (Table 2)

\begin{tabular}{|c|c|c|c|c|c|}
\hline & \multicolumn{2}{|c|}{ Survivors $(n=13)$} & \multicolumn{2}{|c|}{ Non-Survivors $(n=6)$} & \multirow[b]{2}{*}{ p-Value } \\
\hline Outcome & Mean \pm SD & Median (IQR) & Mean \pm SD & Median (IQR) & \\
\hline GCS & $6.92 \pm 3.45$ & $5(5-9)$ & $3.67 \pm 1.37$ & $3(3-4)$ & 0.017 \\
\hline APACHE II & $21.62 \pm 6.0$ & $23(21-26)$ & $31.33 \pm 2.73$ & $32(29-34)$ & 0.002 \\
\hline Admission SOFA & $6.46 \pm 2.29$ & $7(4-8)$ & $7.83 \pm 1.72$ & $7(7-8)$ & 0.21 \\
\hline 48 h SOFA & $2.85 \pm 1.57$ & $2(2-3)$ & $6.40 \pm 4.15$ & $8(5-8)$ & 0.06 \\
\hline Ejection Fraction & $39.38 \pm 8.35$ & $40(35-45)$ & $25.83 \pm 7.36$ & $30(25-30)$ & 0.003 \\
\hline $\mathrm{PaO} 2 / \mathrm{FiO} 2$ & $180 \pm 129$ & $109(82-300)$ & $199 \pm 160$ & $109(102-291)$ & 0.75 \\
\hline Lactate at Admission & $3.39 \pm 2.89$ & $2.6(1.4-3.6)$ & $4.38 \pm 1.03$ & $4.4(4-4.6)$ & 0.095 \\
\hline
\end{tabular}

SD=Standard Deviation; IQR=Interquartile Range; GCS =Glasgow Coma Scale; APACHE = Acute Physiology and Chronic Health Evaluation; SOFA= Sequential Organ Failure Assessment; $\mathrm{PaO}_{2}=$ partial pressure of oxygen in arterial blood; $\mathrm{FiO}_{2}=$ fractional inspired oxygen concentration 
CT imaging of the cervical spine showed no bony or spinal cord injury in any of the patients. CT imaging of the brain showed abnormality in $36.8 \%(n=7)$ patients. Chest $X$ ray showed features of pulmonary oedema in $74 \%(n=14)$ patients. Echocardiography was done on all the patients. It revealed a moderate to severe left ventricular dysfunction with a mean ejection fraction (EF) (\%) of $35.11 \pm 10.17$ for the entire study population. Non survivors had a significantly low EF (\%) as compared to survivors [25.83 \pm 7.36 vs $39.38 \pm 8.35$, $(\mathrm{p}=0.003)]$. (Table 2$)$

Vasopressor support was needed in 68\% (n=13) patients. Mechanical ventilator support was required in $89.5 \%(n=17)$ patients. (Table 1)The indications for invasive ventilation were low GCS, hemodynamic instability and pulmonary oedema leading to hypoxia.

The mean duration of ventilation (days) was similar in survivors and non survivors [3.88 \pm 3.57 vs $4.33 \pm 4.13$, ( $p=0.96$ )]. But non survivors could not be weaned from ventilator due to their severe illness, while survivors were weaned rapidly with significant ventilator free days [0 days vs $6.27 \pm 5.27$, ( $\mathrm{p}=0.001)$ ]. The average hospital LOS and ICU LOS for the study population was $9.21 \pm 6.8$ days and $6.05 \pm 4$ days respectively. Non survivors deteriorated rapidly as evidenced by their shorter hospital LOS $[4.33 \pm 4.13$ vs $11.46 \pm 6.7,(p=0.02)]$ and ICU free days [0 days vs $4.62 \pm 3.4$ days, $(p=0.00)]$ reflecting the severity of the disease in non survivors. (Table 3)

\begin{tabular}{|c|c|c|c|c|c|}
\hline & \multicolumn{2}{|c|}{ Survivors (n=13) } & \multicolumn{2}{|c|}{ Non-Survivors $(n=6)$} & \multirow[b]{2}{*}{ p-Value } \\
\hline Outcome & Mean \pm SD & Median(IQR) & Mean \pm SD & Median (IQR) & \\
\hline Hospital LOS (Days) & $11.46 \pm 6.7$ & $8(8-15)$ & $4.33 \pm 4.13$ & $2(2-8)$ & 0.02 \\
\hline ICU LOS (Days) & $6.85 \pm 3.91$ & $6(4-10)$ & $4.33 \pm 4.13$ & $2(2-8)$ & 0.094 \\
\hline ICU Free Days & $4.62 \pm 3.47$ & $4(3-5)$ & 0 & 0 & 0 \\
\hline Ventilator Days & $3.88 \pm 3.57$ & $3(2-4)$ & $4.33 \pm 4.13$ & $2(2-8)$ & 0.96 \\
\hline Ventilator Free Days & $6.27 \pm 5.27$ & $5(3-6.5)$ & 0 & 0 & 0.001 \\
\hline \multicolumn{6}{|c|}{ Table 3. Outcomes in Survivors and Non-Survivors } \\
\hline
\end{tabular}

\section{DISCUSSION}

Stress cardiomyopathy or Takotsubo cardiomyopathy (TC) was first described in 1991 by Sato from Japan.(7) This clinical entity is characterized by a transient left ventricular dysfunction along with new onset electrocardiographic changes and elevated cardiac troponins often mimicking acute coronary syndrome.(8) It can occur in all age groups (Takuya Nagata et al) ${ }^{(9)}$ and has four variants. Inverted or reverse TC is the common variant in younger patients. When compared to the other three variants reversed TC was associated with very low $\mathrm{EF}$, although the left ventricular dysfunction resolved faster and had a better prognosis. (3)

Incidence of suicidal hanging is low among ICU admissions ${ }^{(10)}$ and hence data on stress cardiomyopathy following suicidal hanging in an ICU is limited to case reports and case series. In most of the case reports the victims were young females. Our study also showed a female predominance of $63.2 \%$. The present study population was young with no comorbid illness. This is comparable with the other case reports. ${ }^{(11,12)}$

CT imaging of the cervical spine did not show any abnormalities in our patients. This was consistent with other studies on suicidal hanging.(13,14) CT imaging of the brain showed no significant pathology in survivors and non survivors except in one patient who demonstrated features of hypoxic ischemic encephalopathy (HIE).The significantly low GCS in non survivors suggest that they might have suffered a more serious neurologic insult but this could not be confirmed with repeat imaging as they deteriorated rapidly.

The ventilator support was needed for a short duration of $4.03 \pm 3.64$ days which is comparable with another study. $(10,13)$ We also observed that the requirement of mechanical ventilation and vasopressor support did not affect the outcome. The $\mathrm{PaO}_{2} / \mathrm{FiO}_{2}$ ratio and admission lactate in non survivors were comparable to survivors.
The mean EF of $(35.11 \pm 10.17)$ in our study population was comparable with other studies.(3,15) In our study the non survivors had a severe left ventricular dysfunction (EF less than 29\%) when compared to survivors. The outcome following the development of stress cardiomyopathy is good due to the reversible nature of the condition and death was low as observed in the previous studies.(4,9) However we observed a high mortality of $31.6 \%$. This high mortality in our study could have been confounded by the fact that in our study population non survivors had a poor neurologic status on admission which by itself carries a poor prognosis ${ }^{(10)}$ and high admission APACHE II score even though the cardiac dysfunction was reversible.

The complications observed among few patients who got discharged were ischemic stroke, radiculopathy, vocal cord palsy and sub arachnoid haemorrhage.

Given the short course of illness leading to early discharge of survivors and death in non survivors in our study population, evaluation of recovery of cardiac function and the duration to recovery could not be done. This was a major limitation in our study.

\section{CONCLUSION}

Stress cardiomyopathy as a complication is a relatively uncommon entity in ICU patients admitted following suicidal hanging. This is a reversible condition when identified and treated early and may significantly change the course of illness. Lack of sufficient data in suicidal hanging unlike judicial hanging warrants further larger studies to support our findings and outcomes in this population.

\section{REFERENCES}

[1] Sane MR, Mugadlimath AB, Zine KU, et al. Course of near-hanging victims succumbed to death: a seven year study. Journal of Clinical and Diagnostic Research 2015;9(3):HC01-HC03. 
[2] Rao D. An autopsy study of death due to suicidal hanging-264 cases. Egyptian Journal of Forensic Sciences 2016;6(3):248-54.

[3] Ramaraj R, Movahed MR. Reverse or inverted takotsubo cardiomyopathy (reverse left ventricular apical ballooning syndrome) presents at a younger age compared with the mid or apical variant and is always associated with triggering stress. Congestive Heart Failure 2010;16(6):284-6.

[4] Ahmed S, Ungprasert P, Ratanapo S, et al. Clinical characteristics of Takotsubo cardiomyopathy in North America. North American Journal of Medical Sciences 2013;5(2):77-81.

[5] Knaus WA, Draper EA, Wagner DP, et al. APACHE II: a severity of disease classification system. Critical Care Medicine 1985;13(10):818-29.

[6] Vincent JL, Moreno R, Takala J, et al. The SOFA (Sepsisrelated Organ Failure Assessment) score to describe organ dysfunction/failure. On behalf of the Working Group on Sepsis-Related Problems of the European Society of Intensive Care Medicine. Intensive Care Med 1996;22(7):707-10.

[7] Dote K, Sato H, Tateishi H, et al. Myocardial stunning due to simultaneous multivessel coronary spasms: a review of 5 cases. Journal of Cardiology 1991;21 (2):203-14.

[8] Ghadri JR, Wittstein IS, Prasad A, et al. International Expert Consensus Document on Takotsubo Syndrome (Part I): clinical characteristics, diagnostic criteria, and pathophysiology. European Heart Journal 2018;39 (22):2032-46.
[9] Nagata T, Mohri M. The clinical features and outcomes of patients with Takotsubo syndrome: the experience at an emergency general hospital. Internal Medicine 2018;57(5):641-5.

[10] Karanth S, Nayyar V. What influences outcome of patients with suicidal hanging. J Assoc Physicians India 2005;53:853-6.

[11] Gnanavelu G, Sathiakumar DB. Reversible left ventricular dysfunction in suicidal hanging. J Assoc Physicians India 2008;56:545-6.

[12] Sengupta S, Mungulmare K, Wadaskar $\mathrm{N}$, et al. Inverted Takotsubo cardiomyopathy after attempted suicidal hanging-two cases. Indian Heart Journal 2016;68(Suppl 1):S52-S6.

[13] Renuka MK, Kalaiselvan MS, Arunkumar AS. An analysis of the predictors of mortality and morbidity in patients admitted after suicidal hanging to an Indian multidisciplinary Intensive Care Unit. Indian Journal of Anaesthesia 2017;61(7):538-42.

[14] Penney DJ, Stewart AH, Parr MJ. Prognostic outcome indicators following hanging injuries. Resuscitation 2002;54(1):27-9.

[15] Viswanathan S, Muthu V, Remalayam B. Pulmonary edema in near hanging. Journal of Trauma and Acute Care Surgery 2012;72(1):297-301. 